\title{
Konsep Pembentukan Akhlakul Mahmudah Melalui Dzikir Menurut Komunitas Tarekat Syattariyah Jamaah Surau Al-Izzah Jalan Bromo Medan
}

\author{
Eprina Gustina1, Parluhutan Siregar ${ }^{2}$, Agusman Damanik ${ }^{3}$ \\ Universitas Islam Negeri Sumatera Utara \\ Corresponding Author :- Eprinagustina76@gmail.com
}

ABSTRACT
Penelitian ini mengkaji tentang konsep pembentukan akhlakul mahmudah
memalui zikir menurut komunitas tarekat syattariyah surau al-izzah jalan bromo
untuk mengetahui fungsi zikir dalam membentuk akhlakul mahmudah dan
mengetahui bagaimana pengalaman komunitas tarekat syattariyah di surau Al-
izzah medan denai tentang berzikir. Berzikir dapat memberikan nutrisi kepada
hati yang lara akibat terlena dengan dunia.berkhalwat dan uzlah sesuai yang
terdapat dalam tarekat merupakan salah satu cara untuk membatasi hati dari
kehidupan dunia yang memabukkan .zikir dalam artiyaan mengingat Allah Swt
dapat dilakukan dengan kapan saja dan dimana saja baik secara lisan mauoun
dalam hati.pada hakikatnya zikir adalah perbuatan hati.zkir merupakan sebuah
kesadaran spiritualsebuah kesaran yang menghasilkan kenikmatan dan sadar
tidak pantasnya berperilaku tidak baik. Untuk mencapai tujuan tersebut para ahli
tasawuf menyarankan para ahli tasawuf menyarankan agar manusia selalu
berupanya untuk memperbaiki akhlaknya dengan cara melatih diri dengan
menempuh jalan tarekat. Tarekat adalah sebuah jalan untuk menempuh dunia
tasawuf agar dekat dengan allah.senantiasa memperbaiki diri (akhlak) yang
zahir dan batin dan menjujung perintah Allah SWT menurut kadar masing-
masing.dalam tarekat ada beberapa amalan cara untuk mendekatkan diri kepada
allah dengan cara zikir rabitah,suluk,Riyadh,tafakur,uzlah muraqabah,amalan
zikir ini menjadi pusat perhatian bagi pengamal tarekat karena zikir sebagai
penyucian diri dari tahapan takhali untuk itu zikir sebagai bentuk usaha
mensucikan diri dari hal-hal tercela sehingga bisa sedekat mungkin dengan Allah
SWT.

\section{PENDAHULUAN}

Ajaran Islam dibawa Rasulullah SAW pada masa awal dan dilaksanakan secara murni oleh para pemeluknya. Ketika Rasulullah wafat, cara beramal dan beribadah para sahabat dan para tabi'in masih tetap memelihara dan membina ajaran Rasul. Mereka disebut amalan salaf AL-Shalih dimulai pada abab pertama hijriyah ada perbincangan perkembangan tentag ilmu tahuid (teologi) islam, dan selanjutnya ada formulisasi pemahaman syariah. pada abad kedua hijriyah mulai muncul "Tasawuf" dan selanjutnya kajian tasawuf terus berkembang dan meluas serta menyebar mulai terpengaruh dengan kajian pengetahuan dari luar. Salah satu yang mempengaruhi tasawuf dari luar adalah filsafat yunani,india, maupun persia. 
Cybernetics: Journal of Research and Educational Studies

Volume 2 Nomor 4, Oktober 2021

Halaman 30-47

Tasawuf merupakan petualangan batin yang penuh keasyikan dan sarat dengan pesan- pesan spiritual yang dapat menentukan batin mausia, sebagai suatu sistem penghanyatan keagamaan yang bersifat esoterik. tasawuf sudah menjadi wacana kajian akademik yang senantiasa aktual sacra kontekstual dalam kajian setiap pemikiran islam. Apalagi ditengah situasi-situasi masyarakat yang mengarah pada dekandensi moral, yang pengaruhnya mulai terasa dalam kehidupan secara langsung, masalah tasawuf mulai mendapat perhatian dan dituntun perannya secara aktif mengatasi masalah tersebut.

Oleh karena itu tasawuf secara universal menepati posisi substansi dalam kehidupan manusia. Bila sudah menyinggung tasawuf maka ada yang namanya tarekat, sufisme dan tarekat merupakan wacana dan praktik keagamaan yang cukup populer di indonesia bahkan akhir-akhir ini kecenderungan sufistik telah menjangkau kehidupan masyarakat kelas menengah sampai masyarakat kelas atas (elit) dengan angka pertumbuhan yang cukup signifikan terutama di daerah perkotaan. Menguatnya gejala sufistik yang terjadi pada lapisan masyarakat mengindisasikan bahwa nilai- nilai yang terkandung dalam sufisme dan tarekat secara psikologis mampu membawa anak bangsa ini menuju masyarakat yang lebih bermartabat dan manusiawi,sehingga terekat diharapkan dapat mengatasi sebagian persoalan hidup terutama dalam bidang moralitas.

Semakin banyak kelalaian seseorang dari kewajiban dalam beragama akan menghasilkan tindakan yang tidak baik dalam berperilaku,sebaliknya, orang yang beriman dan beramal shalih, akan memiliki hati yang sehat mampu memahami banyak pelajaran dan peringatan dalam menuntun hati agar lebih terkondisikan. Kesadaran seseorang dalam mendekatkan diri kepada allah swt berawal dari diri sendiri yang mana kesadaran itu adalalah bukti cinta Allah Swt kepada hambanya. Adanya hal tersebut perlunya adanya renungan atau perhatian penuh mengenai pandangan jauh kedepan untuk mendapatkan arah dan kemungkinan tindakan yang lebih bermakna dalam kehidupan manusia, manusia perlu mengembalikan aktivitas perenungan dalam kehidupan untuk mengoreksi diri, perenungan yangs dilakukan dan diinternalisasikan dalam diri manusia dapat menjadikan hati lebih bersih dan mampu berperilaku baik.

Berzikir dapat memberikan nutrisi kepada hati yang lara akibat terlena dengan dunia. Berkhalwat ( menyepi) dan uzlah (menyendiri) sesuai dengan ajaran yang terdapat dalam tarekat merupakan salah satu cara untuk membatasi hati dari kehidupan dunia yang memabukkan. Keadaan yang diperoleh jiwa pada saat berkhalwat akan berdampak bagi hati dalam menyikapi jiwa yang sedang sakit dan segala hal yang mengarah pada hal-hal yang menjahui syari'at, orang yang memperbanyak zikir maka syurga baginya, banyak menyebut Allah 
Cybernetics: Journal of Research and Educational Studies

Volume 2 Nomor 4, Oktober 2021

Halaman 30-47

Swt dalam setiap hembusan nafas dan menjahukan dari perbuatan tidak manfaat, maka jelaslah tempat kelak dia akan kembali.

Zikir dalam artinya mengingat Allah Swt dapat dilakukan dengan kapan saja dan dimana saja baik secara lisan maupun dalam hati, karena pada hakikatnya zikir adalah perbuatan hati, hendaknya seorang hamba senantiasa berzikir dalam ruang dan waktu dimanapun dan kapan pun baik dalam keadaan sehat maupun sakit sehingga Allah swt senantiasa hadir dalam ingatan, adanya hal demikian dapat memotivasi untuk senantiasa berbuat keabaikan dan malu untuk berbuat kemungkaran.

Orang yang memiliki kesadaran moral akan senantiasa jujur,sekalipun tidak ada yang melihatnya. Tindakan orang yang bermoral tidak akan menyimpang dan berpegang teguh pada nilai-nilai yang sesuai dengan ajaran syariat. Hal ini terjadi karena tindakan orang yang bermoral itu berlandaskan kesadaran, bukan karena paksaan tetapi berdasarkan kesadaran moral yang timbul dari dalam diri Perilaku baik seseorang berawal dari hati yang mampu menjauhkan diri dari penyakit-penyakit hati. Adapun penyakit hati terbagi menjadi lima hal diantaranya sebagai berikut: pertama, banyak bergaul yang tidak manfaat, kedua, panjang angan- angan, ketiga, bergantung pada selain Allah Swt, keempat, kenyang dan banyak tidur, kelima, perkara di atas termasuk perkara paling besar yang merusak hati, Diam merupakan salah satu rukun ibadah, karena dengan diam seseorang dapat memusatkan konsentrasi pikiran dan hatinya. Jika seseorang telah membiasakan sikap diam, maka akan mudah baginya untuk khusyuk dalam setiap ibadahnya, termasuk zikir.

Tohari dalam bukunya yang berjudul Jalan Lurus Menuju Ma'rifatullah7 menjelaskan zikir sebagai jalan terdekat menuju Allah Swt terbagi menjadi empat bagian diantaranya: pertama, zikir lalai (zikir hanya sebatas ucapan bibir), kedua zikir sadar (masih terdapat godaan hati muncul dan terlihat), ketiga, zikir khusyuk (hati sudah sepenuhnya hadir menempati ruang), keempat, zikir ghaibah (zikir yang dapat melupakan segalanya kecuali Allah Swt).

Zikir merupakan sebuah kesadaran spiritual, sebuah kesadaran yang menghasilkan kenikmatan taat dan sadar tidak pantasnya berperilaku tidak baik. Zikir yang sempurna akan mewujudkan sebuah kesadaran dalam diri seseorang secara visual mampu menghasilkan sebuah kebahagiaan ketika melakukan ketaatan dan sebaliknya. Selain itu zikir mampu membentuk perilaku menjadi baik. Untuk mencapainya tidak ada seorang pun yang mampu, kecuali dengan terus- menerus berzikir kepada-Nya. Ruh atau hati yang dipenuhi oleh zikir akan menjadi energi positif yang mengalir ke seluruh jiwa dan raga untuk membersihkan dan memurnikan ruh.Orang yang gemar dalam berzikir identik 
dinamakan tarekat, karena setiap dalam amalan tarekat disandarkan untuk selalu senantiasa berada dalam zikir dan selalu mengagungkan nama Allah Swt.

Bila sudah meyinggung tasawuf maka ada namanya tarekat. Sufisme dan tarekat merupakan wacana dan praktek keagaamaan yang cukup populer diindonesia bahkan akhir- akhir ini kecenderungan sufistik telah menjangkau kehidupan masyarakat kelas atas dengan angka pertumbuhan yang cukup signifikan terutama di daerah perkotaan. Menguatnya gejala sufistik yang terjadi pada lapisan masyarakat, mengindisasikan bahwa- bahwa nilai yang terkandung dalam sufisme dan tarekat secara psikologis mampu membawa anak bangsa ini menuju masyarakat yang lebih mertabat dan manusiawi, sehingga tarekat dapat mengatasi sebagian persoalan hidup terutama dalam bidang moralitas.

Akhlak merupakan upanya untuk mengembangkan segala potensi yang ada disetiap diri manusia dengan terbiasa membiasakan perilaku- perilaku terpuji dan membangun situasi serta kondisi untuk tumbuh dan berkembangnya perilaku terpuji dan membangun situasi serta kondisi untuk tumbuh dan berkembangnya perilaku terpuji dalam diri seseorang. Akhlak merupakan salah satu kesempurnaan ajaran Islam tetapi dengan berkembangnya zaman telah terjadi pergeseran nilai dan penurunan akhlak, sebagaimana yang terjadi diindonesia, sebagian mayoritas islam penduduknya yang dahulu dikenal ramah, berbudaya, dan memiliki moral yang baik dan akhlak yang begitu tinggi, Namun pada dekade ini mengalami penurunan akhlak akibat terkikis gaya hidup, budaya barat dan arus globalisasi yang kuat tanpa filter yang cakap, sehingga hal berakibat terkikisnya jati diri bangsa dan berpengaruh juga terhadap nilai-nilai kehidupan yang diperilhara menjadi goyah bahkan berangsur hilang.

Dalam hal ini semua elemen masyarakat harus terus berupanya melakukan perbaikan- perbaikan guna mengatasi masalah tersebut. Terlebih pada dunia pendidikan dengan berbagai cara untuk mewujudkan generasi bangsa yansg berkualitas dan berakhlak mulia dari memberikan arahan, bimbingan kebiasaan baik, keteladanan, pengawasan ,dan penamaan akhlak sejak dini. Sesuai dengan ajaran islam sebagai rahmat Allah bagi semesta alam. Kerahmatan ini merupakan nilai dan ajaran agama islam yang sejak kemunculannya pada abda ke -7 masehi yang dibawa oleh Rasulullah Saw, sebagai gerakan pembaharauan moral (akhlak) dan sosial yang meiliki peran dalam pembentukan akhlak dan keperibadian manusia, pada saat itu, islam datang untuk memperbaiki masalah akhlak bangsa arab, hadirnya Islam telah menghapuskan perilaku atau sikap jahilinyah yang telah lama menjadi sikap bangsa Arab itu sendiri. 
Cybernetics: Journal of Research and Educational Studies

Volume 2 Nomor 4, Oktober 2021

Halaman 30-47

Melalui keteledanan Rasulullah saw masyarakat jahiliyah menjadi masyarakat yang beradab,meninggalakan kebiasaan yang negatif ( mazdmumah) dan mengganti dengan kebiasaan yang positif (mahmudah ) dengan bahasa lain dari jalan kegelapan menuju jalan yang terang benderang berupa ad-al- islam (agama islam),betapa islam sangat menjujung tinggi akhlak, dengan berakhalakul kariamah menjadikan manusia yang beruntung didunia dan diakhirat dan kita akan mampu menjalin hubungan baik kepada semua elemen masyarakat. Pendidikan akhlak memiliki koleransi yang kuat dengan pendidikan tasawuf karena ajaran tasawuf pada dasarnya memfokuskan pada kehidupan rohani, dimana sipelakunya akan memiliki sebuah entitas yang memiliki karakter- karakter yang mulia, dalam ilmu tasawuf dikenal dengan jenis taswuf akhlaqi yang berkonsentrasi pada perbaikan akhlakul mahmudah, bentuk tasawuf ini berupanya pada upanya-upanya menghindarkan diri dari akhlak -akhlak yang tercela dan mewujudkan akhlak yang terpuji, sehingga dapat dikatakan bahwa akhlak merupakan awal perjalanan tasawuf, sedangkan tasawuf akhir perjalanan akhlak demikian pendapat sebagian ulama.

Untuk mencapai tujuan tersebut, para ahli tasawuf menyarankan agar manusia selalu berupaya untuk memperbaiki akhlaknya dengan cara melatih diri( Riyadh salah satunya menempuh jalan tarekat, sebagai pendapat imam alGhazali yang dikutip Abdul Qadir disitu Al-Gazhali menegaskan betapa pentingnya tarekat sebagai penyangga paling penting bagi tasawuf,lebih lanjut Al-Ghazali menyakinkan bahwa tasawuf tanpa tarekat ibarat jiwa tanpa badan dan nutrisi tasawuf hanya didapat melalui tarekat).

Disini tanpak jelas bahwa tarekat sebuah jalan untuk menempuh dunia tasawuf agar dekat dengan Allah swt. Senantiasa memperbaiki diri ( akhlak) menjahui larangannya baik zahir maupun batin dan menjujung tinggi perintahperintah Allah swt menurut kadar masing- masing.Dalam tarekatnya memilih beberapa asmalan cara untuk mendekatkan diri kepada Allah diantaranya adalah dzikir rabitah,suluk,Riyadh,tafakur ,uzlah,muraqabah,amalan dzikir ini menjadi pusat perhatian bagi pengamal tarekat karena dzikir sebagai penyucian diri (tazkiyah an-nafs) dari tahapan takhali untuk itu dzikir sebagai bentuk usaha mensuciakn diri dari hal- hal tercela sehingga bias berada sedekat mungkin dengan Allah swt.

Salah seorang ulama pembaharuan yang terkenal disumatera barat adalah syekh Burhauddin, Syekh Burhanuddin telah banyak dikenal dan diperbincangkan para ilmuan, baik dalam libelatur maupun dari laporan bangsa eropa lainnya. Salah satu sumber utama yang menjelaskan lahirnya pembaharuhan islam diminang kabau berasal dari naskah kuno Arab melayu. 
Cybernetics: Journal of Research and Educational Studies

Volume 2 Nomor 4, Oktober 2021

Halaman 30-47

Syekh Burhanuddin menjadi sosok yang terkenal di Minang kabau berkat ketinggian ilmu,serta menjadi tokoh penting penyebaran islam ajaran syattariyah dipengujung abad 17 di mana dari beliau inilah muncul sederatan ulama-ulama yang besar yang dulunya belajar dan berguru kepadanya baik yang masih tetap menyebarkan tarekat syattariyah atau yang pada akhirnya memilih lain selain Tarekat Syttariyah.Tarekat Syattariyah dengan segala kekhasannya memainka peran penting dalam penyebaran penting dalam penyebaran Islam di Ranah Minang,Tarekat ini lebih diterima oleh masyarakat dan cenderung tidak mengalami banyak penolakan dari orang minang pada umumnya, karena metodenya lebih damai dan lembut menyikapi budaya lokal masyarakat minang kabau.

Syekh Burhanuddin mengembangkan pemikirannya melalui pendidikan disurau, murid- murid yang belajar disurau sayattariyah terbuka untuk mempelajari seluruh rangkaian pengetahuan islam. Bahakan sebagian besar masyarakat Minang telah mengenal dan mengamalkan ajaran yag dibawanya. Tidak terbatas dengan masyarakat Minang di Sumatera Barat, masyarakat Minang yag berada diluar Sumatera Barat sampai sekarang tetap Menjadikan Syekh Burhanuddin sebagai waliyullah dan seorang ulama besar.

\section{METODE PENELITIAN}

Jenis penelitian ini termasuk penelitian lapangan (Field Research) dengan pendekatan kualitatif. Alasaan menggunakan pendekatan kualitatif adalah karena penelitian kualitatif dapat menjelaskan suatu fenomena dengan sedalamdalamnya dengan cara pengumpulan data. Terkait hal tersebut maka penelitian kualitatif sangat mendukug untuk situasi saat ini dan untuk judul skripsi saya. Dengan penelitian kulitatif, peneliti dapat dengan mudah untuk menggali informasi yang lebih dalam terkait suatu topik penelitian yang nantinya informasi yang didapatkan dapat digunakan untuk menentukan tujuan penelitian. Informan dalam penelitian adalah orang atau pelaku yang benarbenar tahu dan menguasai masalah, serta terlibat langsung dalam masalah penelitian. Dalam penelitian ini, sumber data primer adalah langsung dari pengikut tarekat syattariyah yaitu narasumber yang menguasai permasalahan dalam penelitian ini yaitu Syeikh Tuanku Hasan Basry selaku Ulama Syattariyah Kecamatan Medan Denai. Data sekunder peneliti mengambil dari pernyataan murid/jamaah diluar Tarekat, tokoh agama disekitar musholla yang bukan bagian dari komunitas Tarekat, serta buku-buku, jurnal dan skripsi yang berhubungan dengan penelitian ini. 
Cybernetics: Journal of Research and Educational Studies

Volume 2 Nomor 4, Oktober 2021

Halaman 30-47

\section{HASIL DAN PEMBAHASAN}

\section{Sejarah Perkembangn Tarekat Syattariyyah Di Kota Medan}

Perkembangan ajaran tarekat Syattariyah Syekh Burhanuddin ke kota Medan tidak dapat dipisahkan dari latar belakang kebiasaan hidup orang minang yang suka pergi merantau,Merantau itu sudah kebiaasaan orang minang dan bagian yang tidak akan terpisahkan, Dikatakan oleh Ronidin bahwa merantau bagi orang minang kabau merupakan tradisis yang mengangkar erat, merantau memiliki makna yang signifikan bagi putra inang kabau dalam proses pematangan konsep diri maupun pematangan ekonomi,istlah orang minang kabau tidak akan menjadi besar sebelum merantau.

Menurut tokoh masyarakat minang dikota medan diantara nya Usman pelly menyatakan bahwa kedatangan orang Minang ke Medan jahu sebelum masuknya penjajahan Hindia belanda, bahakan sejak zaman kerajaan Pagaruyung dengan rajanya Aditya warman sudah terjadi kontak hubungan antara Minang kabau dengan Melayu di Sumatera Timur.

Migrasi orang Minang ke kota Medan (dahulu disebut tanah deli) banyak yang terjadi pada masa pemerintahan Kesultanan deli yang ke-9 dibawah raja Sultan Makmun AL-Rasyid,banyak perkebun an baru dibuka dan pusat-pusat perdagangan yang didirikan ,hal ini merupakan peluang besar bagi masyarakat pendatang untuk merubah tahap hidup dan ekonomi,akhirnya orang minang juga datang ke Medan,kemudian berasimilasi dan beradaptasi dengan masyarakat Melayu sehingga akhirnya mereka mengalami proses melayunisasi,Disebutkan dalam kesultanan deli adalah: Orang-orang melayu deli adalah campuran antara orang melayu aceh,karo,mandailing,jawa,bugis,minang dan suku laiinnya. Suku pendatang ini mengalami proses pemelayuan (masuk melayu) dengan berkartultrasi dengan adat melayu,beraga islam dan memakai bahasa melayu,proses melayunisasi ini terkait dengan minat untuk merahi kesukseksesan diperantauan,baik dalam hidup ekonomi maupun politik.Ketika kelompok pendatang ingin memperoleh peluang yang sama dengan penduduk asli,mereka merubah dirinya menjadi Melayu yang secara otomatis harus masuk islam.

Berdasarkan dari kutipan tersebut diatas jelas bahwa kedatangan orang Minang ke medan lebih didominasi oleh motivasi ekonomi,oleh karena itu falsafah orang melayu sebagai penduduk asli memiliki kesamaan dengang falsafah hidup orang minang ,maka proses sosialisasi dan adaptasi orang minang yang merantau kemedan terjadi lebih mudah diterima dan lebih cepat berkembangnya.

Jumlah terbesar masyarakat minang yang merantau ke Medan adalah yang berasal dari padang pariaman, dengan itu mereka secara langsung membawa 
paham-paham ajaran dan pengalaman rirual dan keagamaan yang mereka peroleh dari kampung halamanya,beberapa bukti dapat diketahui dengan berdirinya surau-surau Syekh Burhanuddin dibeberapa kelompok komunitas daerah asal merantau seperti surau Syekh Burhanuddin dijalan A,R Hakim gang seto,mesjid Syekh Burhanuddin Gang Langgar Ujung, surau yang didirikan para perantau dengan maksud tempat pengembangan tarekat Syattriyah Syekh Burhanuddin di Medan,bukti lain adalah paham mando'a dan urang siak.

Ronidin menyatakan bahwa : Citra rasa kebersamaan sebagaimana dikembangkan disurau akan terasa faedanya ketika sedang berada dirantau,Dirantau,semasa orang Minang akan dipandang sebagai saudara,saudara yang dimaksud itu bisa jadi sebagai saudara yang memang salapiak skatidura,saudara sekampung, saudara sedaerah,maupun saudara sesama minang kabau. Para perantau yang berasal dari padang pariaman inilah yang mula-mula berkumpulkan beberapa orang kemudian mereka mendirikan surau di Medan.fungsi surau yang didirikan adalah selain wadah untuk melaksanakan ritual ibadah,keagamaan ,mengaji dan aktivitas pengembangan paham Syekh Burhanuddin lainnya, surau tersebut berfungsi untuk sebagai tempat menapung para pemuda yang merantau, Disurau itulah mereka awalnya tidur, mengaji belajar ilmu bela diri serts pencak silat dan ilmu kebatinan,mengembangkan ajarann agama sambil mencari-cari kehidupan dengan berdagang dan lain-lainnya.

Dalam perkembangan ajaran Syekh Burhanuddin di Kota Medan yang pada awalnya melalui para labai dan tuanku dari ulakan, selanjutnya karena komunitas masyarakat Minang mulai bertambah dan menyebat diseluruh kota medan,maka dalam beberapa aktivitas keagamaan sangat dibutuhkan keberadaan para labai yang menjadi pemimpin keagamaan. Pola hidup orang minang yang merantau kemedan juga hampir sama dengan pola hidup didaerah asal.Kehidupan berkelompok dengan membentuk organisasi kekerabatan, yang asal usul daerah,asal kesukuan,da nasal usul kenagarian masih terlihat di daerah rantau.

Cukup banyak organisasi perkumpulan atau perkumpulan orang minang perantauan dikota medan,seperti organisasi kedaerah/kenagarian: Persatuan Keluarga Padang Pariaman (PKDP),Generasi Muda Padang Pariaman (GEMPAR),Ikatan Keluarga Gasan Saiyo (IKGS),Ikatan Keluarga Subur Kuraitaji(IK-SUKUR),Ikatan Keluarga Bayur(IKB),Ikatan Keluarga Matur (IKM),Ikatan Keluarga Sungai Jariang (IKJS), dan lain-lainya. Meskipun tidak ditemukan arsip atau data yang tertulis mengenai sejarah tahun masuknya dan berkembangnya ajaran syekh burhanuddin kemedan,tetapi berdasarkan cerita yang berkembang pada masyarakat minang dikota medan bahwa ajaran syekh 
Cybernetics: Journal of Research and Educational Studies

Volume 2 Nomor 4, Oktober 2021

Halaman 30-47

burhanuddin pertama kali dibawa oleh para murid syekh burhanuddin ulakan, hal ini diperkuat dengan keterangan labai syafaruddin bahwa ulama ulakan yang pertama datang pertama kemedan adalah tuanku shaliah yang memiliki nama asli Muhammad daud beserta beberapa orang labai diantaranya Labai Tangih,Labai Suman,Labai saman,Labai apa,Labai Pidik,Labai Zainuddin,Labai Wahab,Labai Khaidir,Labai Munaf,Labai Sahrian Tukang,dan Labai Abok,kedatangan ke Medan tahun 1955 atas undangan masyarakat Minang yang pada waktu itu akan mengadakan peringatan Maulid disurau Syekh Burhanuddin di gang seto,Disurau ini pertama kali diadakan acara maulid nabi Muhammda Saw dengan acara tradisi badakia dan diakhiri dengan makan bersama, acara dilaksanakan selama dua hari dia malam.

Sejak pertama datang pada tahun 1957 Tuanku Saliah keramat akhirnya sering di medan melakukan pembinaan.kedatangna tuanku shaliah Ulakan baik itu sebagai ulama dan juga dipandang sebagai orang yang keramat,dia lahir dipadang panjang pada tahun 1890 dan meninggal digoba dipasar panjang sei sariak pada tahun 1974,dari cerita orang padang pariaman yang ada dimedan bahwa tuanku Saliha selain menjadi tokoh spritual bagi pengikiut syekh burhanuddin diperantauain ia juga terkenal memiliki kesaktian yang dapat menyembuhkan berbagai macam penyakit baik yang zahir maupu yang bersifat kebatinan

Tidak lama dari kedatangan para labai tersebut,disusul dengan kedatangan para Tuanku, diantarnya tuanku yang mula-mula ke Medan adalah Tuanku Muhammad yakub yang dipanggli Angku Akuik,Tuanku Kuniang Akhiruddin,TuankuHitam,Tuanku Muhammad sinaro,dan Tuanku Hasan basri, Orang minang pergi merantau yang pertama mereka cari adalah surau dan induk semang. Disurau tempat mereka tinggal bersama suka dan duka, memperoleh pembinaan rohani dan para labai dan Tuanku yang bermukim disurau,inilah yang mengokohkan mereka menyatukan mereka dan melecut motivasi mereka.

Kehidupan surau mengajari mereka untuk tidur sederhana dan lebih mengutamakan kebersamaan,Dengan demikian proses berkembangnya ajaran Syekh Burhanuddin tidak lepas dari pernatauan yang membangun surau dimedan disertai pembinaan oleh labai dan tuanku dariulakan.pembinaan yang dilakukan yaitu mengajarakan anak-anak mengaji disurau, memimpin acara syukuran, musibah kematian dan menjadi tabib dalam menyebuhkan penyakit yang bersifat mistik dan guna-guna.

Banyak surau-surau yang menganut paham syekh burhanuddin di medan yang memang dibangun dan didirikan oleh masyarakat minang yang berasal dari padang pariaman, namun untuk sekarang pengaruh dari Syekh 
Cybernetics: Journal of Research and Educational Studies

Volume 2 Nomor 4, Oktober 2021

Halaman 30-47

Burahnuddin sudah ditinggalkan oleh masyarakat Minang dikota medan, tapi masih ada mesjid yang masih memegang teguh ajaran Syekh Burhanuddin yaitu Mesjid Raya Syekh Burhanuddin yang di Jalan Rawa II Gang Langgar Ujung. Dimesjid inilah semua kegiatan dari pengalaman ajaran tasawuf Syekh Burhanuddin Yang masih dijalankan.

\section{Komunitas Tarekat Syattariyyah Di Kota Medan}

Perkembangan ajaran Syekh Burhanuddin tidak dapat dilepaskan dari sejarah awalnya perkembangan tarekat Syattariyah di wilayah melayu-indonesia yang ditandainya kembalinya Abdurauf Al-Sinkili.masa kembalinya al-sinkili dari Haramayn ini dapat dianggap sebagai awal perkembangan tarekat Syattariyah termasuk Syekh Burhanuddin kedunia melayu-indonesia.

Tarekat syyatariyah pertama kali dibawah oleh Tuaku Saliaha yang memiliki nama asli Muhammad Daud dan pertama tahun 1957 mengikuti pembinaan tentang tarekat sayyatriyah dan belum memiliki komunitas dan disusul dengan tuanku lainnya tuanku Muhamad Yakub yang tidak dijelaskan kapan datang kemedan ia mengajarkan tarekat di gang seto ujung dimushollah ditempat mengajarkan tarekat syattariyah dan itu belum berkembangnya hanya daerah sekitar dan tokoh lainnya datanglah tokoh tuanku Kuniang Akhiruddin ikut juga mengembangkan tarekat sayyatariyah didaerah gang seto dan menyebar dibeberapa daerah terdekat dengan berdakwa dan perantauan orang minang yang membawa tarekat tersebut.

Pada tahun 1973 tahun pertama datang tuanku Hasan Basri datang kekota medan untuk menyebarkan tarekat sayyattariyah digang seto dan menggantikan tuanku Muhammad yakub yang telah wafat dengan mengajarkan tarekat sayyatariyah dan mendakwah menyebarkan tentang tarekat sayyatariyah kepada jama'ah lainnya dan berdirinya pusat komunitas tarekat sayyatariyah yaitu dibangunnya musollah Al Izzah yang berada dijalan Bromo Kecamatan Denai di disitulah berkembangnnya tarekat syyatariyah yang diajarakan oleh tuanku Hasan Hasri dengan berdakwah kemesjid-mesjid dan mengajarkan jama'ah tentang tareat sayyatariyah dan berkumpulnya dan terbentuknya tarekat sayyatariyah dan tempatnya di Musollah Al Izzah .

\section{Pengaruh Dzikir Terhadap Akhlakul-Kharimah Menurut Tarekat Syattariyah}

Manusia diciptakan Allah SWT dalam bentuk yang paling sempurna dalam melanjutkan tugas khalifah dibumi ini.untuk menjadi seorang kahlifah tentunya harus memiliki akhlak yang baik,hal ini menujukkan betapa pentingnya akhlak sebagai karakter bangsa,bangsa akan menjadi jaya jika warga negaranya terdiri dari atas masyarakat yang berak hlak terpuji,sebaliknya jika warga Negara rusak,maka rusak lah Negara itu. 
Cybernetics: Journal of Research and Educational Studies

Volume 2 Nomor 4, Oktober 2021

Halaman 30-47

Akhlak terpuji dalam islam mengatur kehidupan manusia untuk menjalani kehidupan dunia,dan ajaran akhirat untuk kehidupan yang kekal,perwujudan nilai- nilai akhlak sesuai dengan norma-norma kebutuhan yang oleh islam disebut dengan amal sholeh. Orang yang berakhlakul karimah dapat menciptakan keadaan yang tentram dan nyaman, tidak pada kesusahan tidak ada persaingan yang tidak sehat dan masalah-masalah yang membuat resah.Allahn menjanjikan kepada manusia syurga dan dunia,pahala dan dosa, Maka jika seseorang yang baik dan berakhlakul karimah allah menjanjikan pahala baginya,sebaliknya jika manusia tersebut senantiasa melakukan perbuatan zalim dan melanggar aturan- aturan Allah maka baginya adalah siksa.

Shaik Amin Alaudin dalam kitabnya,menjelaskan sesungguhnya zikir kepada Allah SWT,sebagai metode (jalan) untuk memperbaiki perilaku menjadi akhlak terpuji dan sebagai pembersih hati,zikir sebagai metode untuk menghilangkan sesuatu yang akhlaknya tercela.zikir sebagai jalan untuk menghubungkan arus perjalan sufi dengan ketetapan yang sudah ditetapkan oleh Allah SWT,sehingga kita melihat bahwa para sufi merupakan orang yang tidak kuatir akan persoalan dunia, para sufi sentiasa sabar qana'ah ,tawakkal, dan ridha disetiap keputusan allah Swt,dan perjalanan akhir yaitu berzikir kepadaAllah SWT dalam membersihkan hati.

Zikir berfungsi sebagai pembentukan akhlak melalui proses pembersih hati (tahiri al-qalb) dari sifat-sifat akhlak tercela (akhlakul mazmumah )dan mengisi dengan sifat-sifat yang terpuji (akhlakul mahmudah).menurut ibnu athaillah zikir merupakan suatu cara untuk membersihkan hati darin sifat-sifat tercela bagi para salik yang menempuh jalan tasawuf dan menghiasi dengan akhlak terpuji (akhlakul mahmudah).

Allah berfirman dalam Al-Qurean surah al-imran ayat 191, Artinya: "(yaitu) orang-orang yang mengingat Allah sambil berdiri atau duduk atau dalam keadaan berbaring dan mereka memikirkan tentang penciptaan langit dan bumi seraya berkata : "ya Tuhan kami tidalah engkau menciptakan ini dengan sia-sia,maha suci engkau,maka peliharalah kami dari siksa neraka.

Ash-sharqawi mengatakan bahwa zikir memiliki tiga tahap sebagaimana yang dikutip oleh Amin Najas,yaitu :

1. Zikir paling utama memperbaiki diri(„,ilaju an-nafs)

2. Zikir sebagai proses sebagai penyuciandan pembersihan ruhani (iman) dalam hati (tazkiyah ruh al-iman fi al-qalb)

3. Zikir sebagai bentuk muraqabah secara rahasis (muraqabah lissir).

Dengan demikian dapat disimpulkan bahwa hubungan zikir dan akhlakul karimah itu saling berkaitan dalam segala hal zikir itu mendidik,dan membimbing akhlak manusia lebih baik menuju akhlak yang mahmudah.karena 
zikir mampu memberikan hal segala macam membuang kotoran-kotoran yang ada pada dalam hati,serta mempu membentuk jiwa dengan baik sehingga akan melahirkan kepribadian yang mulia adalah hasil dari pengalaman zikir kepada allah yang dilakukan secara Istiqamah,khusu" dan bersumgguh-sungguh.

Tata Cara pelaksanaan dzikir pada Komunitas Tarekat Syattariyyah Jamaah Surau Al-Izzah Jln bromo Medan

Zikir adalah ajaran yang paling penting dalam bertarekat,Rasulullah Saw bersabda "ketahuilah bahwa sesungguhnya zikir itu akann memenenangkan sebaik-baik zikir adalah dengan membaca Laa ilaha illallah. Zikir adalah mendekatkan diri kepada Allah SWT,Dan berzikir hal yang penting dalam bertarekat,tarekat ini juga banyak melafalkan kalimat-kalimat tahuid asmaul husna sebagain dari wirid dan zikir tersebut. Melaksanakan wirid atau zikir dalam tahriqah syattariyah hendaknya seseorang memperhatikan aturan-aturan tersebut:

1. Dalam keadaan normal hendaknya seseorang bacaannya wirid terdengar dengan diri sendiri

2. Harus suci dari najis,baik dari pakaian,badan, tempat maupun apa saja yang dibawanya.

3. Harus suci dari hadats,baik besar maupun kecil.

4. Harus menutup aurat sebagaimana dalam keadaan shalat,baik laki-laki maupun perempuan

5. Tidak boleh berbicara

6. Harus menghadap kiblat

7. Harus duduk

8. Tashawwur yaitu membaca dengan memejamkan matanya setelah membaca al-ikhlas,al-mu'awwidzatain,istigfar

9. Memaknai dan menjiwai wirid yang dibaca sampai akhir jika tidak bisa hendaknya memerhatikan dengan mendengarkan bacaan wiridnya.

\section{Tata Cara Pelaksaan Zikir Tarekat Syattariyah}

1. Shalat taubah dengan niat

Artinya : aku niat shalat sunnat taubat dua rakaat karena Allah ta'ala. Allahu akbar dan kemudian setelah siap sholat taubah maka dibarengi dengan zikir:

Subahnallah $33 \mathrm{kali}$

Allhamdulillah $33 \mathrm{kali}$

Allahu akbar 33 kali

Amaliyah zikir tarekat syattariyah sedikitnya 3 kali atau 10 kali, dan bahkan diutamakan sampai 10 kali bahkan lebih banyak karena zikir lebih banyak lebih baik akan tetapi tidak meninggalkan ma'na dalam lafaznya sebab jika zikir tidak 
Cybernetics: Journal of Research and Educational Studies

Volume 2 Nomor 4, Oktober 2021

Halaman 30-47

dibarengi dengan makna diumpamakna sebiji padi dan tidak isi nya maka,ketika mengucapkan laa ilaha illa Allah ingat dalam hati tidak ada yang disembah dengan benar dan wujudnya atau tidak yang berkuasa kecuali allah atau tidak ada yang pasti keberadaannya kecuali allah,setelah berzikir laa ilaaha illa Allah 33 kali kemudian illah Allah 33 kali dan zikir Allah 33 kali dan huwa 33 kali.

Mulanya membaca zikir dengan lafasz "la" di tarik dari bahu kiri kebawah dilingkarkan pada puser lalu naik kebahu kanan kemudian lafaz "ilaaha" dimiringkan pada welikat tengah dan lafaz "illaAllahu"dihantamkan pada posisi sanu bari,tepatnya dibawah payudara sebelah kiri yang bentuknya seperti kuncup bunga melati,maka dari itu dihati sanubarilah serta lafadz Allah itu menciptakan cahaya yang bersinar.

Etika orang hendak berzikir duduk bersimpuh menghadap kiblat bertawassul dengan membaca surah al fatihah untuk baginda rasulullah Saw,membaca al-fatihah untuk para guru,kemudian memabaca al-ikhlas satu kali,membaca an-nas satu kali dan melanjutkan istigfar 3 (tiga) kali,membaca shalawat 3 (tiga) kali kemudian posisi kedua tangan berada diaras kedua paha,mata terpenjam berzikir dengan kita,lalu kita bertawasul kepada guru, karena guru itu adalah khalifah Rasulullah dan khalifah Allah swt.

Kemudian melafalkan sambil menarik \memajangkan Laa ilaaha illa Allah tiga kali atau sepulu kali atau bisa sampai dengan 100 kali dan jangan sampai lupa maknany kemudian dilanjutkan dengan membaca lafaz muhammadur Rasulullah.

Ma'na laa ilaaha illa Allah tidak ada yang diwajib untuk disembah dengan wujudnya kecuali allah,tiada yang wajib disembah dengan sebenarnya kecuali Allah,tiada yang berkuasa kecuali allah,dimana saja yang terdapat kebenaran tunggal dan menghilangkan juga mengisbatkan sifat Uluhiyyah,ma'na kalimat laa ilaaha illah Allah mebghilangkan dari segala sesuatu dan menetapkan Allah SWT.Lafaz ini menujukkan bahwa laa ilaaha illa Allah substansi maknanya nafi'dan istbath.laa ilaha illa Allah mencangkup ma'na menghilangkan sesuatu selain allah dan menetapkan Allah swt asal dari segala yang ada.

Fungsi Dzikir Menurut Pemahaman Komunitas Tarekat Syattriyyah Jamaah Surau Al-Izzah Jln Bromo Medan

Tujuan dalam berzikir adalah mengingat Allah SWT dalam setiap saat dan menjalin hubungan kejiwaan antara manusia dengan allah,agar arus kesadarannya stabil,sehingga tumbuh rasa dekat,cinta dan hormat kepadanya dengaan artiaan aktivitas zikir,iman seseorang sebagai respon kepada Allah SWT.

Menurut pak midi salah satu jamaha tarekat fungsi zikir itu sangat berpengaruh pada membentuk akhlak sangat berpengaruh untuk saya karena 
dengan berzikir hati saya menjadi tenang dan merasa dekat deangan Allah dulu nya saya termasuk jahu dari allah shalat saya pun jarang hanya satu kali dalam seminggu dan kemudian kawan saya mengenalkan saya pada tuanku hasan basri yang mengajarkan tarekat sayyatriyah dan kami datang menemui tuanku dan kemudian saya menceritakan masalah hidup saya dan pada saat itu tuanku menyuruh saya memimum yang sudah dibacakan beliau dan malamnya saya ikut berzikir bersama beliau dan mengajarkan saya tentang berzikir dan shalat taubat dan begitu seterusnya saya ikut kepengajian beliau dan ikut berzikir pada malam jum'at di musholla beliau yang letaknya dijlan bromo ini dan allhamdulillah sampai sekarang saya bisa lebih baik dan lebih dekat kepada allah dengan berzikir.

Saya telusuri lagi menurut jamaha tarekat sayyatariyah lainnya yaitu pak sudirman menurutnya berzikir itu sangat banyak fungsinya dengan pengalaman saya sebagai jama'ah tarekat saya dulunya saya sering sekali berdebat tentang masalah ekonomi dan saya kemudian menemui tuanku hasan basri dan menceritakan masalah saya kepada beliau dan beliau bertaya kepada saya apa saya jahu dari allah swt dan kemudian beliau mengajak saya untuk ikut kesalah satu kajian yaitu ikut kajian yang tempat nya di mesjid syekh burhanuddin yang di gang langgar dan kemudian saya ikut berzikir dan tuanku hasan basri menyuruh saya untuk shalat taubat dan saya melaksanakan itu kalau tidak salah selama seminggu dan itu terlihat dalam diri saya semakin dekat dengan allah dengan cara berzikir dan itu terlihat sudah jelas ada perubahan dalam diri saya dan keluarga mungkin saya sadar saya jahu dari allah dan kurang dalam bersyukur.

Menurut Tuanku Hasan Basry fungsi dalam bertarekat itu adalah secara umum untuk mendekatkan diri kita kepada allah swt untuk menentukan akhlakul karimah dan yang diresapi dengan batin kita sendiri menjahukan dari sesuatu kemaksiatan zahir dan maksiat batin seperti ria,sombong,dan menjahukan kita dari Allah SWT dan maksiat zahir adalah melakukan hal yang dilanggar Allah SWT.

Fungsi zikir itu adalah membentengi diri kita dari gangguan setan,petunjuk jalan kebaikan,mendekatkan kita kepada Allah SWT,penggerak batin dan berzikir menjahukan kita dari sifat yang tercela menuju sifat yang terpuji.

Hubungan Antara Pelaksanaan Dzikir Dengan Pembentukan Akhlakul Mahmudah Menurut Pemahaman Komunitas Tarekat Syattariyyah Jamaah Surau Al-Izzah Jln.Bomo Medan

Tarekat yaitu jalan menuju pada allah dengan melalui pengalaman zikir yang berkepanjangan,maka dari itu zikir ialah membersihkan hati dari pada sifat -sifat mazmumah (tercela), maka tersisilah dengan sifat terpuji,sifat terpuji yang 
Cybernetics: Journal of Research and Educational Studies

Volume 2 Nomor 4, Oktober 2021

Halaman 30-47

mewarnai perilaku dengan membersihkan hati.dengan berzikir kita terjahu dari maksiat dan membentuk akhlalakul karimah,dan alat untuk membersihkan hati dari segala maksiat yaitu dengan berzikir.zikir itu bikulli syaiin syakkallah yaitu setiap sesuatu itu ada alat pembersihnya,wassalatul qalbi zikrullah alat pembersih hati itu dengan kita berzikir kepada allah swt.yaitu bersih dari sifat mazmumah atau sifat yang tercela dan diisi dengan sifat yang tepuji yaitu dengan berzikir maka itulah disebut dengan akhlak batin.

Menurut tuanku sinaro hubungan antara zikir dan akhlak itu sangat erat kaitannya karena dalam kita berzikir kita bisa mendekatkan diri kepada allah dan dengan dekat dengan allah maka hati menjadi tenang dan terbentuknya akhlak yang baik. Menurut zukkifli jamaha tarekat syattariyah hubungan antara antara berzikir dengan akhlak itu sangat terhubung Karena dalam berzikir dengan kuhsyuk berharap ridho allah maka dari situ lah tercipta perangai yang baik kita selalu mengingat allah dan takut untuk berbuat dosa ataupun berbuat akhlak tercela yang dilarang oleh allah swt dengan berzikir allah akan menjahukan kita dari hal yang buruk karena kita senantiasa mengingat alla $h$ bukan dengan pikiran tapi dengan hati jika allah telah ridho kepada seorang hambanya maka allah akan mempermudah jalannya untuk berbuat baik termasuk membentuk perangai yang baik.

Implikasi Dzikir Terhadap Pembentukan Akhlak Menurut Pengalaman Komunitas Tarekat Syattariyyah Jamaah surau Al-Izzah Jln.Bromo Medan

Zikir sebagai metode yang paling efektif untuk membersihkan hati dan mencapai kehadiran Allah SWT.tidak ada yang lebih efektif dalam menyelematkan diri dari hukuman Allah SWT,zikurullah diartikan dengan sebagai piagam persahabatan dengan Allah SWT,sehingga barang siapa yang dianugrai zikir berarti telah diyatakan bershabatan dengan Allah SWT.ziki sebagai cahaya yang sangat terang benderang,melalu zikir yang dipadukan dalam bentuk perenungan yang benar,seseorang akan memperoleh jiwa yang utuh,murni,dan menyeluruh seperti emas, dalam zikir jiwa seseorang diserahkan semua kepada allah swt dalam bentuk pengorbanan yang luhur,Akhirnya dengan zikir seseorang pasti akan memperoleh keadaan fana' dan baqa'yang berarti ia merasakan dirinya tak terpisahkan dari Allah swt bahkan dari segi lahir sekalipun.

Berzikir adalah membimbing jiwa untuk mendekatkan dan pengenalan terhadap zat allah swt dengan melalui pembersihan diri dari segala kotoran jiwa(batin) menghiasi cdengan berzikir maka hati kita akan menjadi bersih dan melakukan latihan-latihan ruhaniyah dan melawan hawa nafsu,syahwat serta maksiat sampai jiwa tersambung denga Allah SWT dengan cara berzikir. 
Cybernetics: Journal of Research and Educational Studies

Volume 2 Nomor 4, Oktober 2021

Halaman 30-47

Implikasi zikir membentuk akhlak itu harus bisa mencapai beberapa langkah agar bisa meresapi tarekat yaitu dengan:

1. Tobat yaitu penyesalan dan berjanji tidak akan melakukan dosa yang dilakukan ya dahulu dengan bertobat kita bisa menuju jalan yang benar .

2. Sabar yaitu menahan diri dari dorongan hawa nafsu demi menggapai keridaan tuhannya dan mengganti nya dengan bersungguh-sungguh dan menjalani cobaan Allah terhadapnya.

3. Tawakkal tawakkal adalah menyerahkan semua urusan kepada allah swt membersihklan dari ikhtiar kita yang keliru,dan apa yang ditentukan oleh allah pasti yang terbaik.

4. Husnu zhan (berbaik sangka) yaitu dengan berbaik sangka terhadap keputusan allah karena dengan berbaik sangka maka hati kita akan jadi baik

5. Zikrullah yaitu selalu mengingat allah dalam keadaan apapun karena dengan berzikir itu pertanda hubungan allah dengan diri kita.

6. Bersyukur sikap seseorang untuk tidak menggunakan nikmat yang diberikan Allah Swt dalam melakukan maksiat bentuk syukur yang ditandai dengan kenyakinan hati bahwa nikmat yang diperoleh itu hanya semata dari Allah swt.

\section{KESIMPULAN}

Itulah jalan yang harus ditempuh seseorang untuk bisa mencapai akhlak yang baik dengan kita mengikuti langkah-langkah tersebut insya Allah Allah SWT akan menjaga kita dari akhlak yang tidak baik Berzikir adalah membimbing jiwa untuk mendekatakan dan pengenalan terhadap dzat Allah SWT, melalui proses pemnbersihan diri dari segala kotoran jiwa( batin ), menghiasinya dengan sifat-sifat yang mulia (akhlak kulkarimah) dengan melakukan berbagai serangkaian latihan-latihan ruhaniyah dan perjuangam dalam melemahkan hawa nafsu, syahwat serta maksiat sampai jiwa tersambung dengan -Nya, sehingga hanya Allah SWT yang ada didalamnya dan pada akhirnya hijab (penghalang) antara dirinya dengan Allah SWT terbuka. Implikasi zikir terhadap akhlak adalah untuk memperkukuh akhlakul karimah,membina sikap zuhud,membentengi dari penyakit hati membangun sikap aktif dan positif,memberikan semangat social dan intelektual,peemgendalian hawa nafsu,mendidik menjadi pribadi yang tidak tama', sombong dan riya, proses krisis spiritual,meningkatkan rasa taat dan patuh kepada allah,mengatur dan menata kehidupan manusia modern menjadi akhlak yang mulia. 
Cybernetics: Journal of Research and Educational Studies

Volume 2 Nomor 4, Oktober 2021

Halaman 30-47

\section{DAFTAR PUSTAKA}

Abd al-Rahman Muhammad bin Al-Kumais,Zikr al-jamal bain al-Ibtidal,terj.Abu Harkan,Zikir Bersama;Bid'ah atau Sunnah Solo: al-Tibyan,t.th

Abdirrahman Abi As-Sulami,Adab Ash-Shuhbah,(1990) Mesir:Dar Ash-Shahaba AtTurats, Thantha

Abdullah Ridwan Sani,Muhammad Kadri(2016) "Pendidikan Karakter (Mengembangkan Karakter Anak Islami)",Jakarta:Bumi Aksara

Adam, "Theology", dalam Encyclopaedia of Religion and Ethics, Vol. XII, 293 Al -Muhasibi(1984),Adab An-Nufus,Lebanon:Dar Al-Jayl

Ali Nurdin ,(2010)Sejarah berkembangnya Ajaran Syekh Burhanuddin di Kot Medan.(Tesis pasca sarjana Uinsu) : hlm.

Al-Quzwainy,Mukhtashar Syu'b Al-Iman

Amin Muhammad al-Kurdi,Tanwir al-Qulub fiy Mu'amalati 'Allami alGhuyuub,Surabaya:Pen Bungkul Indah ,t,t hlm

Amir Ahmad Aziz,(2020)Teologi Kaum Tarekat,Bantul:Trussmedia Grafika Amir Ahmad Aziz, (2020)Teologi Kaum Tarekat,Bantul:Trussmedia Grafika Amir Ahmad Aziz, ,(2020)Teologi Kaum Tarekat,Bantul:Trussmedia Grafika Amir Ahmad Aziz,(2020) Teologi Kaum Tarekat,Bantul:Trussmedia Grafika Anwar Roshian, 2010 akhlak tasawuf bandung : pustaka setia

Arman, Rusli, 1981,Plakat Panjang Jakarta:Sinar Harapan

As-safarayani,ghida Al-Albab SYARH Manzhumah Al-Adab(2002),Beirut :Dar Al-Kutub Al-ilmiyyaH, ,jilid II

Asy- Syarqawi, (1976) Nahwa Ilmu Nafs Islamy Iskandaria:al-Hai'ah Litashrih AL-Ammah

Bangun Ahmad Nasution Dan Rayani Hanum Siregar( 2013 )“Akhlak Tasawuf"Jakarta:PT Raja Grafindo Persada

Bangun Ahmad Nasution Dan Rayani Hanum Siregar(2013) "Akhlak Tasawuf"Jakarta:PT Raja Grafindo Persada

Barhauddin (2004),paradigma psikologi islam(Studi tentang Elemen Psikologi dari Al-Qur'an) Yogyakarta:Pustaka Pelajaran

Dokumen Tuanku Hasan Basry,Tokoh Agama \Syekh Mejid Syekh Burhanuddin,tanggal 23 September 2021 pukul 22.30 WIB.

Effendi Djohan, (1995 )“Konsep-konsep Teologis”, dalam Budhy MunawarRachman (ed.), Kontekstualisasi Doktrin Islam dalam Sejarah Jakarta: Paramadina

Faturahman Oman, (2008)Tarekat Syattariyah di Minangkabau ,Jakarta:Prenada Medan Group

Faturhaman Oman, (2008)Tarekat Syattraiyah di Minangkabau,Jakarta:Prenada Media Group 
Cybernetics: Journal of Research and Educational Studies

Volume 2 Nomor 4, Oktober 2021

Halaman 30-47

Furqon M Hidayatullah( 2019)"Besar Sejati Membangun Insan Berkarakter Kuat dan Cerdas"Surakarta :Yuma Pustaka

Hawi Akhmal (1988),Kompetensi Guru Pendidikan Agama Islam, Cet.2, Jakarta:PT,Raja Gara Amin Abdullah An-Naqsabandi, Ma Huwa attasawwuf, Ma Hiya ath-thariqah an naqsabandiyah (Bagdhdad:Dar alkutub Alauddin Amin,Ma Huwa at-Tasawuf.

Hazm Ibnu(1988),Al-Akhlaq wa As-Siyar,Kairo:Dar Al-Masyriq Al-'Arabi, http:/ / citrariski.blogspot.com/2011/02/makalah-tarekatsyattariyah.html?m=1, Dirilis pada hari jum'at,11 februari 2003

https://sarjanaekonomi.co.id/purposive-sampling/, diakses pada pukul 16.09 tanggal 14 Agustus 2020.

Ibn Ali Nay , Asy-Syahud,Fiqh Al-Quran wa As-Sunnah,Juz IV

Idrus H,A.,( 1996)Menuju Insan Kamil Profil Manusia Berkualitas,Jakarta :CV Aneka 1996

Iqbal Muhammad Irham(2018),Akhlak Tasawuf,Islamic Character Building, Medan: Wal Ashri Publishing 